\title{
DETERMINAÇÃO DE ISOFLAVONAS NO HIDROLISADO ENZIMÁTICO DE FARELO DE SOJA
}

\author{
A. D. D. CAVALCANTI ${ }^{1}$, M. R. BUENO ${ }^{1}$, J. R. MELO ${ }^{1}$, D. MANTOVANI ${ }^{2}$ e G. M. ZANIN ${ }^{1}$ \\ ${ }^{1}$ Universidade Estadual de Maringá, Departamento de Engenharia Química \\ ${ }^{2}$ Universidade Estadual de Maringá - Campus Umuarama, Departamento de Tecnologia \\ E-mail para contato: andre.delano@ hotmail.com
}

\begin{abstract}
RESUMO - As isoflavonas, flavonoides naturalmente presentes nos grãos tem sido alvo de muitas pesquisas devido à sua atividade antioxidante, atuando nos radicais livres e, desta forma, diminuindo processos oxidativos nos organismos. O farelo de soja é um subproduto da indústria extratora de óleo de soja que possui alto teor proteico. Realizouse a hidrólise enzimática do farelo de soja, no intuito de se obter um hidrolisado que pudesse ser direcionado para a alimentação humana. Também foi realizada a hidrólise controle para comparação com a hidrólise enzimática. Previamente a isso, realizou-se a extração de carboidratos em parte do farelo de soja, devido aos problemas digestivos que certos carboidratos da soja apresentam. A enzima utilizada foi a ALCALASE, e foram realizados testes tais como o teor de proteína solubilizada (aprox. $32 \mathrm{mg} / \mathrm{mL}$ para o hidrolisado enzimático), bem como outros métodos analíticos relacionados às isoflavonas como determinação de fenólicos (99 mg/200 mL de hidrolisado enzimático) e flavonoides totais (17 mg/200 mL de hidrolisado enzimático). Também foi medida a capacidade antioxidante pelo método de sequestro de radicais livres (DPPH•) obtendo-se uma perda de $1 / 3$ da concentração inicial de DPPH• para a melhor amostra. Determinou-se também o teor de algumas isoflavonas por cromatografia líquida de alta eficiência (CLAE), obtendose concentrações inferiores de algumas das isoflavonas medidas para o hidrolisado enzimático em relação ao hidrolisado controle.
\end{abstract}

\section{INTRODUÇÃO}

Embora a maior parte do farelo de soja ainda seja destinada à fabricação de rações animais, muitos processos têm sido desenvolvidos com o objetivo de obter produtos mais refinados, destinados diretamente ao consumo humano ou à produção de ingredientes proteicos (aditivos alimentares) (Stenzel, 2007).

Os alimentos de origem vegetal apresentam compostos não-nutrientes (fitoquímicos) com atividades biológicas ditas promotoras da saúde, tais como atividades antioxidante, anti-inflamatória e hipocolesterolêmica. (Harborne e Willians, 2000). As isoflavonas são flavonoides, um tipo de antioxidante naturalmente presente na soja que atuam nos radicais livres e, consequentemente, tendo funções de controle e prevenção dos processos oxidativos e degenerativos que ocorrem no organismo 


\section{9 a 22 de outubro de 2014 \\ Florianópolis/SC}

(Vilarta et. al, 2007). Também são denominadas fito-estrógenos, devido à capacidade de provocar uma resposta semelhante ao estrogênio em experimentos com animais (Genovese e Lajolo (2003) apud Callou (2009). Os seres humanos estão expostos a uma série de agentes oxidantes que podem causar danos oxidativos às biomoléculas (lipídeos, proteínas e ácidos nucléicos) que poderiam levar a um grande número de patologias incluindo câncer e arteriosclerose. Assim, presume-se que a ingestão de antioxidantes capazes de neutralizar os radicais livres possa ter um papel importante na prevenção destas doenças (Harborne e Willians, 2000; Fritz et. al, 2003).

A composição global dos hidrolisados enzimáticos em aminoácidos é semelhante à do material inicial, e, além disso, os hidrolisados proteicos mostram vantagens, como melhor solubilidade, estabilidade térmica e relativamente alta resistência à precipitação por agentes como íons metálicos e pH (Clemente, 2000). Em relação à hidrólise enzimática relacionada diretamente com as isoflavonas, um trabalho que pode ser citado é o de Wu e Muir (2010) que realizaram a hidrólise enzimática da farinha de soja para verificar se a hidrólise enzimática afeta a presença das isoflavonas no produto a base de soja. Foram testadas três proteases diferentes, e o estudo mostrou que os produtos à base de soja que sofreram hidrólise das proteínas apresentaram quantidades significativas de isoflavonas, sendo que o conteúdo e a composição das isoflavonas foram grandemente afetadas pelas condições de reação aplicadas e pela presença de atividade de $\beta$ glicosidase (contaminante) nas proteases comerciais. Os resultados dos autores ainda indicaram que os produtos após sofrerem hidrólise apresentaram uma concentração de agliconas 10 vezes superior em relação à farinha de soja.

O objetivo principal deste estudo foi a determinação do teor de flavonoides e da capacidade antioxidante do hidrolisado enzimático de farelo de soja. Os principais objetivos específicos foram realizar a hidrólise enzimática do farelo de soja; determinar o teor de proteína do hidrolisado; determinar a capacidade antioxidante in vitro e caracterizar e quantificar as isoflavonas presentes no hidrolisado.

\section{MATERIAIS E MÉTODOS}

\subsection{Materiais}

O farelo de soja desengordurado tostado utilizado nos experimentos possuia em torno de $46 \%$ de proteína e foi cedido pela indústria de extração de óleos da Cocamar, situada em Maringá, Paraná. Após a extração do óleo, o farelo foi submetido à dessolventização com vapor. Neste ponto do processo o farelo foi coletado à temperatura em torno de $60{ }^{\circ} \mathrm{C}$. A enzima ALCALASE® 2.4L da Novozymes Latin America Ltda e foi fornecida pela empresa Tovani Benzaquen Representações Ltda, localizada em São Paulo-SP. As isoflavonas padrão (daidzina, genistina, glicitina, daidzeína, genisteína e gliciteína) foram obtidas da Chromadex, enquanto os demais reagentes foram obtidos da Sigma-Aldrich.

\subsection{Métodos}

Extração dos carboidratos: A extração alcoólica foi realizada com etanol $70^{\circ} \mathrm{GL}$ (Siqueira et. al, 


\section{9 a 22 de outubro de 2014 \\ Florianópolis/SC}

2013) com a mistura de 25 g de farelo de soja para $150 \mathrm{~mL}$ de álcool que foram deixados por 4 horas sob temperatura de ebulição e agitação magnética, em erlenmeyers que permaneceram em refluxo. Em seguida, o farelo foi filtrado, e seco em estufa para secagem a $100^{\circ} \mathrm{C}$, até massa constante.

Hidrólise enzimática do farelo de soja: As dispersões foram preparadas em frascos erlenmeyers utilizando-se $10 \mathrm{~g}$ de farelo de soja em $100 \mathrm{~mL}$ de água destilada. Foram adicionados 0,78 $\mathrm{mL}$ da enzima ALCALASE® 2.4L. Os frascos foram levados a um Banho Dubnoff TE-053 da Tecnal que foi ajustado à temperatura de $60^{\circ} \mathrm{C}$ e $100 \mathrm{rpm}$ de agitação, onde permaneceram por um período de 2 horas. Após isso, os recipientes foram levados a um banho termostático Tecnal TE-184, ajustado a 90 ${ }^{\circ} \mathrm{C}$ por 15 minutos, para a inativação da enzima. Ao final, o material foi filtrado a vácuo. Para cada ensaio foi feita uma reação controle, ou seja, nas mesmas condições do experimento, porém sem a ad ição da enzima (Stenzel, 2007; Stroher et. al, 2009).

Determinação de Fenólicos Totais: $0,25 \mathrm{~mL}$ do hidrolisado foram adicionados a $2 \mathrm{~mL}$ de água destilada e $0,25 \mathrm{~mL}$ do reagente de Folin-Ciocalteau. Após 3 minutos à temperatura ambiente, adicionou-se $0,25 \mathrm{~mL}$ de solução saturada de carbonato de sódio, sendo os tubos agitados e colocados em banho a $37{ }^{\circ} \mathrm{C}$, durante 30 minutos. As absorvâncias foram determinadas a $750 \mathrm{~nm}$, utilizando espectrofotômetro Shimadzu modelo UVmini-1240. O padrão utilizado para a montagem da curva foi uma solução de $0,1 \mathrm{mg} / \mathrm{mL}$ de catequina e as análises foram feitas em triplicata. (Genovese et al, 2003 apud Callou, 2009).

Determinação de Flavonoides Totais: Uma alíquota de $1 \mathrm{~mL}$ do hidrolisado foi misturada com 4 $\mathrm{mL}$ de água destilada. Em seguida, adicionou-se $0,3 \mathrm{~mL}$ de uma solução de $\mathrm{NaNO}_{2}$ a 5\% (m/v). Após 5 minutos, foram adicionados $0,3 \mathrm{~mL}$ de uma solução de $\mathrm{AlCl}_{3}$ a $10 \%$ (m/v). Após um minuto, adicionou-se $2 \mathrm{~mL}$ de uma solução $1 \mathrm{~mol} / \mathrm{L}$ de $\mathrm{NaOH}$. Foram adicionados 2,4 mL de água destilada. Após agitação vigorosa, a absorvância da mistura foi lida a $510 \mathrm{~nm}$ (Zhishen et. al, 1999 apud Alothman et. al, 2009). Construiu-se uma curva de calibração com uma solução de catequina. Os resultados serão expressos em $\mathrm{mg}$ de equivalente em catequina/200 $\mathrm{mL}$ da amostra e as análises foram feitas em triplicata.

Determinação de Proteína Solubilizada: Adicionou-se $0,1 \mathrm{~mL}$ de amostra a $2 \mathrm{~mL}$ do reagente de trabalho, seguido de agitação e incubação em banho termostático Tecnal TE-184 a $37^{\circ} \mathrm{C}$ por 30 minutos. Previamente à leitura, foi necessário resfriar essa amostra até à temperatura ambiente. A leitura foi realizada a $562 \mathrm{~nm}$ (Smith et. al, 1985). A curva padrão foi preparada com uma solução 1 $\mathrm{mg} / \mathrm{mL}$ de albumina e as análises foram feitas em triplicata.

Sequestro de Radicais Livres (DPPH•): Para a detecção da capacidade antioxidante das amostras, foi utilizado o método de Brand-Williams et. al (1995) modificado. Adicionou-se $0,1 \mathrm{~mL}$ da solução antioxidante em 3,9 mL de uma solução metanólica de $6 \times 10^{-5} \mathrm{~mol} / \mathrm{L}$ de DPPH•. A variação na absorvância foi medida nos seguintes tempos (min): 0, 2, 4, 6, 8, 10, 15, 20, 25, 30, 40, 50, 60, 75, 90 e 105. O comprimento de onda utilizado foi de $515 \mathrm{~nm}$. Empregou-se o antioxidante Trolox $^{\circledast}$ (6-hidroxi-2,5,7,8-tetrametil-2-ácido carboxílico) para que pudessem ser feitas comparações. Para tal comparação, utilizaram-se várias razões de Trolox/ DPPH•, variando de 0,2 até 1,6 (mol/mol). Também foi feita uma amostra controle (adição de metanol puro). 

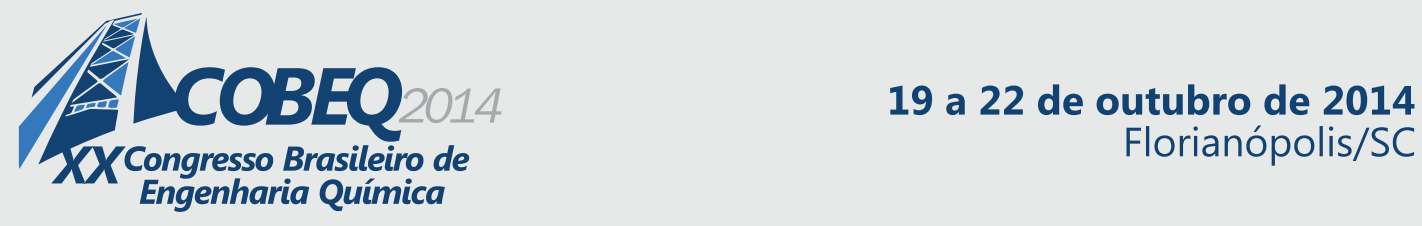

Determinação do Teor de Isoflavonas por CLAE: Para a determinação do teor de isoflavonas, utilizou-se sistema de Cromatografia Líquida de Alta Eficiência (CLAE) Varian modelo 920-LC, com coluna Thermo, modelo Scientific, C18, tipo ODS Hypersil, dimensões: 250 x 4,6 mm, partículas esféricas: $5 \mu \mathrm{m}$. As fases móveis utilizadas foram A: Água Ultrapura $+0,1 \%$ de Ácido acético e B: Acetonitrila $+0,1 \%$ de Ácido acético e vazão constante ao longo da corrida com $1 \mathrm{~mL} / \mathrm{min}$ (regime em gradiente), e temperatura de forno a $35^{\circ} \mathrm{C}$. Seis soluções metanólicas de isoflavonas foram utilizadas para a determinação dos tempos de retenção e para posterior quantificação das possíveis isoflavonas presentes nas amostras: daidzina, glicitina e genistina (glicosídeos), e daidzeína, gliciteína e genisteína (agliconas). Foram injetados volumes de $20 \mu \mathrm{L}$ de mix com diferentes concentrações das isoflavonas diluídas, para confecção das curvas de calibração. Para as amostras realizou-se a secagem dos hidrolisados, de forma a se conseguir massa seca para posterior utilização de um solvente para a extração das isoflavonas. Para avaliação e comparação, foram utilizados dois tipos de secagem e dois tipos de solvente. Os tipos de secagem avaliados foram a secagem em estufa a vácuo a $40^{\circ} \mathrm{C}$ e -600 $\mathrm{mmHg}$, e a secagem por liofilização, enquanto os solventes utilizados foram o metanol $80 \%$ e a acetonitrila 80\%. A estufa utilizada foi uma FANEM Mod. $099 \mathrm{EV}$, enquanto o liofilizador utilizado foi um LabConco Freeze Dry System/ Freezone 4.5. O método de extração, conhecido na literatura como Extração Assistida por Ultrassom (UAE - Ultrasound Assisted Extraction), descrito por Achouri et. al (2005), onde a amostra seca em contato com o solvente extrator permanece no ultrassom por 15 minutos. Utilizou-se uma Lavadora Ultrasonica, da Unique. A quantidade de solvente adicionado para a extração ocorreu de forma que houvessem $20 \mathrm{mg}$ de hidrolisado seco por $\mathrm{mL}$ de solvente (Mantovani et. al, 2013, com algumas modificações). Não foram analisadas as isoflavonas acetil e malonil.

\section{RESULTADOS E DISCUSSÃO}

\subsection{Determinação de Fenólicos Totais/ Flavonoides Totais/ Proteína Solubilizada}

Como pode ser observado na Tabela 1, as amostras geradas por hidrólise enzimática mostraram melhores resultados com respeito aos fenólicos do que as amostras controle, uma vez que a clivagem realizada pela enzima é muito mais intensa e acaba conferindo às amostras quantidade provavelmente maiores de todos os compostos, ainda que seja uma protease com finalidade específica de clivagem de ligações peptídicas, do que as amostras controle, que somente tem como agentes de quebra a água, a temperatura e a agitação.

Em relação à extração de carboidratos, observou-se que o farelo que não sofreu extração mostrou resultados de maior expressão no que diz respeito a teor de fenólicos, uma vez que embora a extração teoricamente seja exclusivamente de carboidratos, podem existir perdas durante as etapas do processo. Exemplos de perdas que podem ter ocorrido no processo foram proporcionadas pelas temperaturas de ebulição durante a extração e também na etapa de secagem em estufa. A temperatura, de aproximadamente $100^{\circ} \mathrm{C}$ e pode ter comprometido também parte dos fenólicos presentes nas amostras que sofreram extração.

As amostras enzimáticas alcançaram maiores quantidades de flavonoides do que as amostras controle. Isso era esperado, uma vez que os flavonoides são uma subcategoria dos fenólicos. Em 


\section{9 a 22 de outubro de 2014 \\ Florianópolis/SC}

relação ao comparativo entre as amostras sem extração dos carboidratos do farelo e com a extração dos mesmos, novamente as amostras sem extração se sobressaíram em relação às outras.

Tabela 1 - Teor de fenólicos totais, flavonoides totais e proteína solubilizada presentes nas amostras de hidrolisado

\begin{tabular}{cccc}
\hline Amostra & $\begin{array}{c}\text { Concentração }(\mathbf{m g} \\
\text { fenólicos/ 200 } \mathbf{~ m L} \\
\text { de amostra) }\end{array}$ & $\begin{array}{c}\text { Concentração }(\mathbf{m g} \\
\text { flavonoides/ 200 } \\
\text { mL de amostra) }\end{array}$ & $\begin{array}{c}\text { Concentração }(\mathbf{m g} \\
\text { proteína/mL) }\end{array}$ \\
\hline $\begin{array}{c}\text { 1- Sem extração, } \\
\text { controle }\end{array}$ & $\mathbf{5 7 , 1 4}$ & $\mathbf{9 , 1 2}$ & 12,56 \\
$\begin{array}{c}2-\text { Sem extração, } \\
\text { enzimática }\end{array}$ & 99,58 & 18,89 & 18,89 \\
\hline $\begin{array}{c}3-\text { Com extração, } \\
\text { controle }\end{array}$ & 3,01 & 2,67 & 2,67 \\
\hline $\begin{array}{c}4-\text { Com extração, } \\
\text { enzimática }\end{array}$ & $\mathbf{8 9 , 8 5}$ & 13,18 & 13,18 \\
\hline
\end{tabular}

Finalmente, é possível observar, de acordo com os resultados, que as amostras enzimáticas apresentaram um maior teor de proteína solubilizada. A ALCALASE $^{\circledR}$ (nome comercial da subtilisina) é uma protease com atuação específica nas ligações peptídicas e, consequentemente, fazendo com que o hidrolisado produzido apresentasse uma quantidade maior de proteína. Os resultados dos hidrolisados enzimáticos também foram condizentes com o trabalho de Ströher (2010).

\subsection{Sequestro de Radicais Livres}

A Figura 1 mostra um comparativo da ação antioxidante de algumas razões de Trolox e dos hidrolisados. É possível observar a diferença de ação antioxidante, que enquanto para o Trolox é na faixa de 20 minutos de reação, os hidrolisados enzimáticos tem seu pico de ação antioxidante entre 80 a 100 minutos de reação. Constata-se que as amostras de Trolox começam oscilando da mesma forma, e apresentam a menor concentração de DPPH• em aproximadamente 20 minutos. Pode-se observar também que, quanto maior a razão de Trolox ${ }^{\circledast} / \mathrm{DPPH} \bullet$, menor a concentração do radical livre atingida. Esse aumento de concentração no gráfico, demonstrado após 20 minutos deve-se ao fato que a absorvância após os 20 minutos estabiliza-se, variando menos que o próprio DPPH• (que apresentou um decréscimo de absorvância ao longo do tempo) sozinho ou nem variando, o que com as curvas padrão ajustadas para os tempos de 20 minutos em diante, resultam em concentrações maiores. É importante frisar duas coisas: a incapacidade antioxidante da amostra 3, que só apresenta crescimento na curva, tendo como justificativa o fato da absorvância estar estabilizada e estar variando menos do que a própria solução de DPPH• sozinha. Também é importante observar o aparente aumento de concentração que as duas soluções enzimáticas apresentam. $\mathrm{O}$ que pode estar ocorrendo é intereferencia da cor do hidrolisado, uma cor amarelada, na absorvância da solução de DPPH•, levando a um aumento da absorvância inicial. Porém, ainda assim, o fato do hidrolisado 
enzimático apresentar capacidade antioxidante faz com que essa absorvância seja reduzida, o que significa um reflexo na concentração do radical que chega a aproximadamente $4 \times 10^{-5}$ mol/L para a amostra 4, um terço menor do que a concentração inicial.

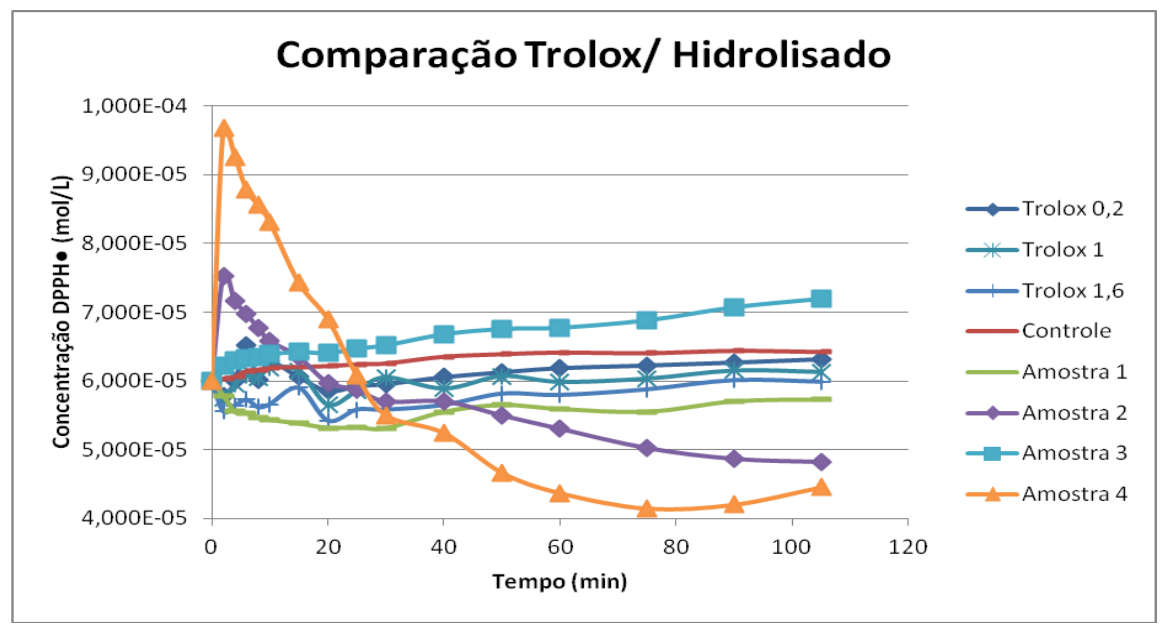

Figura 1 - Comparativo de algumas razões de Trolox/DPPH• com os hidrolisados. Amostra 1: sem extração, controle; 2 : sem extração, enzimática; 3 : com extração, controle e 4: com extração, enzimática.

\subsection{Determinação do Teor de Flavonoides por CLAE}

A Figura 2 mostra o resultado da análise do teor de isoflavonas em cada uma das amostras. A análise do teor de isoflavonas mostrou resultados contraditórios aos que eram esperados em função das análises anteriores. Algumas considerações são necessárias: nenhuma das amostras apresentou o composto daidzina. Os compostos que não sofreram extração possuem uma diversidade maior de isoflavonas, possuindo tanto glicosídeos quanto agliconas, enquanto os que sofreram extração somente possuem as agliconas, que segundo Lui et al (2003) parte das isoflavonas do farelo de soja se perde com a realização da extração alcoólica. Entretanto, a amostra que apresentou maior quantidade das isoflavonas foi a amostra 3, que era a amostra que sofreu extração e foi gerada de uma hidrólise controle, enquanto a amostra 4 mostrou as menores quantidades. Entretanto, é importante frisar que a amostra 2 apresentou capacidade antioxidante e apresentou tanto glicosídeos quanto agliconas, mostrando uma maior qualidade. Outro fato notado foi que os glicosídeos se mostraram sensíveis ao tratamento térmico. Em relação à secagem, pode-se observar que a secagem em estufa se mostrou mais eficiente de modo geral, muito embora as amostras secas por liofilização apresentarem maior quantidade de glicosídeos, o que reitera a importância que o processamento tem sobre a quantidade e diversidade das isoflavonas. Quanto aos solventes, de modo geral o metanol $80 \%$ apresentou os melhores resultados, sendo que os glicosídeos praticamente só apareceram em extrações feitas com o metanol. 

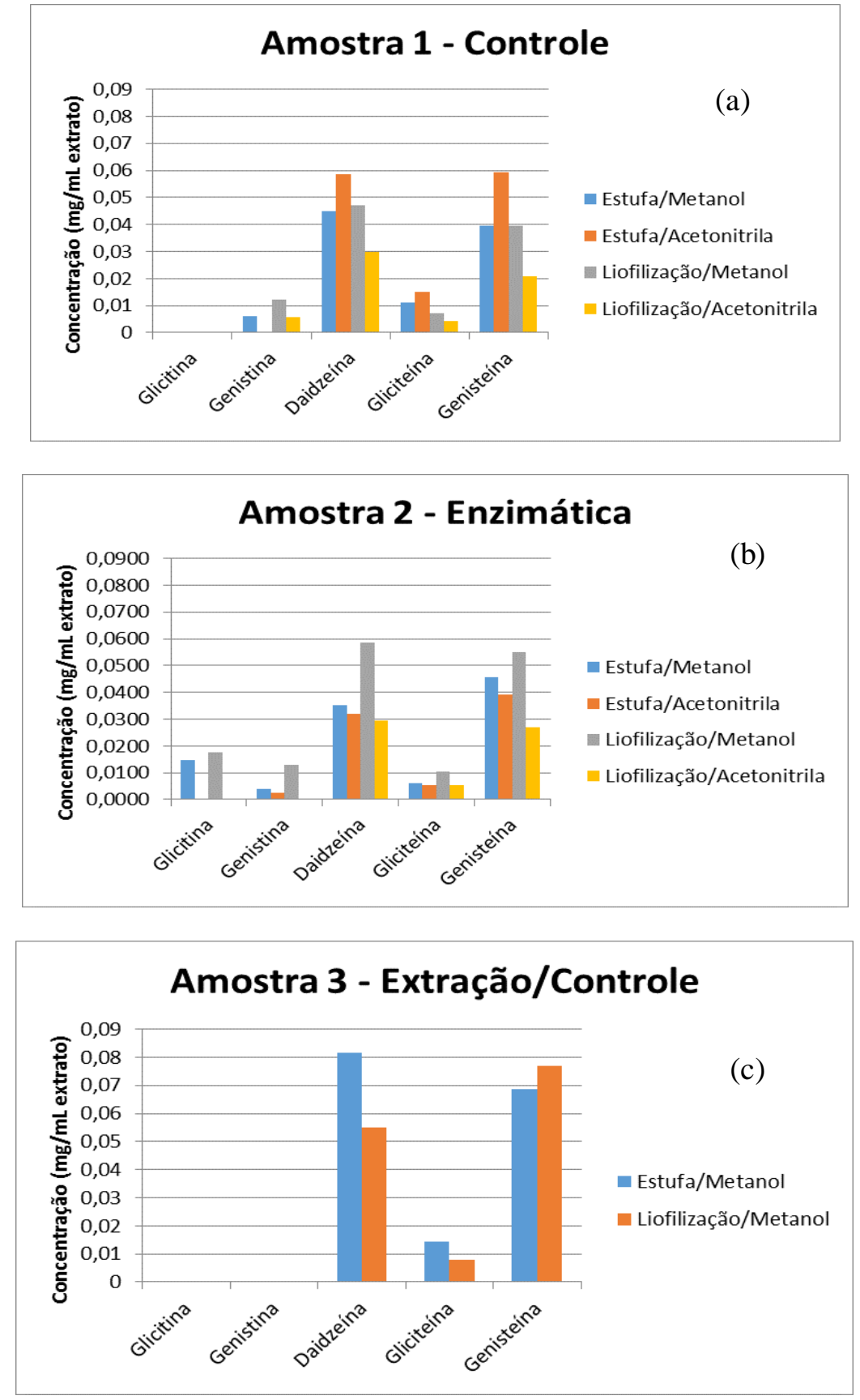


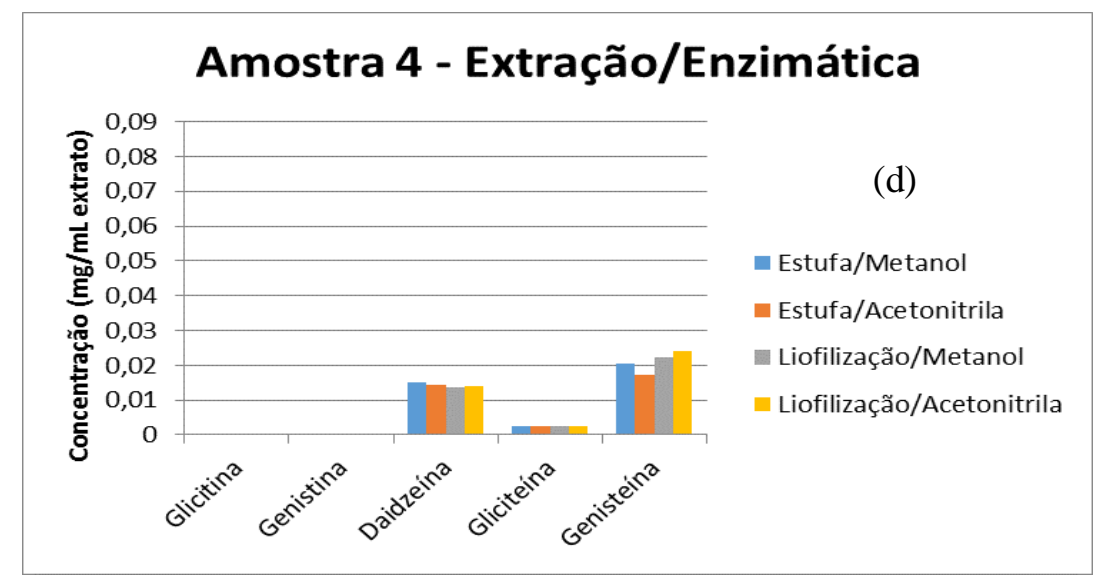

Figura 2 - Isoflavonas presentes nas amostras e suas respectivas quantidades nos diferentes tipos de solvente e secagem. (a) Amostra 1 - Controle; (b) Amostra 2 - Enzimática; (c) Amostra 3 Extração/Controle; (d) Amostra 4 - Extração/Enzimática

\section{CONCLUSÕES}

As amostras enzimáticas mostraram maiores teores dos compostos analisados e maior capacidade antioxidante, o que mostra que a enzima atua na liberação de substâncias antioxidantes. A análise do teor de isoflavonas mostrou que a capacidade antioxidante do hidrolisado não provem das mesmas, ou pelo menos não é a força antioxidante principal. Não é descartado que as isoflavonas possuam capacidade antioxidante; entretanto, no caso do hidrolisado a força antioxidante provem de outra fonte.

*Agradecimentos:à CAPES (financeiro), COCAMAR (farelo) e Tovani Benzaquen (enzima).

\section{REFERÊNCIAS}

ACHOURI, A.; BOYE, J.I.; BELANGER, D. Soybean isoflavones: Efficacy of extraction conditions and effect of food type on extractability. Food Res. Int., v. 38, p. 1199-1204, 2005.

ALOTHMAN, M.; BHAT, R.; KARIM, A. A. UV Radiation-Induced Changes of Antioxidant Capacity of Fresh-Cut Tropical Fruits. Innov. Food Sci. and Emerg. Tech., v. 10, p. 512-516, 2009.

BRAND-WILLIAMS, W.; CUVELIER, M. E.; BERSET, C. Use of a Free Radical Method to Evaluate Antioxidant Activity. LWT-Food Sci. and Tech., v. 28, p.25-30, 1995.

CALlOU, K. R. A. Teor de Isoflavonas e Capacidade Antioxidante de Bebidas à Base de Soja. 124 p. Dissertação (Mestrado em Ciências de Alimentos) - Faculdade de Ciências Farmacêuticas, Universidade de São Paulo, São Paulo, SP. 2009.

CLEMENTE, A. Enzymatic Protein Hydrolysates in Human Nutrition. Trends in Food Sci. \& Tech., v. 11, p. 254-262, 2000.

FRITZ, K. L.; SEPPANEN, C. M.; KURZER, M. S.; CSALLANY, A. S. The in vivo antioxidant activity of soybean isoflavones in human subjects. Nutr. Res., New York, v. 23,p. 479-487, 2003. 
HARBORNE, J. B.; WILliANS, C. A. Advances in flavo noid research since 1992. Phytochem., Oxford, v. 55, p. 481-504, 2000.

LUI, M.C.Y.; AGUIAR, C. L.; ALENCAR, S. M.; SCAMPARINI, A. R.; PARK, Y. K. Isoflavonas em isolados e concentrados protéicos de soja. Ciênc. e Tec. de Alim., v. 23, p. 206-212, 2003.

MANTOVANI. D.; CORAZZA, M. L.; FILHO, L. C.; TAZINAFO, N. M.; RIBANI, M.; COSTA, S. C. Determinação de Teores de Isoflavonas Comercializadas na Forma de Extrato Seco e Manipuladas por Farmácias. Rev. Bras. de Tec. Agro., v. 07, p. 1033-1041, 2013.

SIQUEIRA, P. F.; MIRANDA, L. C.; FRANQUETTO, E. M.; SMOLAREK, F. S. F.; FERREIRA, R. P.; PIVATTO, R. S.; PEDROSO, C. F.; GIORDANO, R. C.; TARDIOLI, P.W.; GIORDANO, R.L.C. Extração de fosfolipídeos residuais em farelo desengordurado de soja. In: XIX Simpósio Nacional de Bioprocessos - X Simpósio de Hidrólise Enzimática de Biomassa, 2013, Foz do Iguaçu. XIX SINAFERM / X SHEB 2013, 2013. v. CD-ROM.

SMITH, P. K.; KROHN, R. I.; HERMANSON, G. T.; MALlIA, A. K.; GARTNER, F. H.; PROVENZANO, M. D.; FUJIMOTO, E. K.; GOEKE, N. M.; OLSON, B. J.; KLENK, D. C. Measurement of Protein Using Bicinchoninic Acid. Anal. Biochem., v. 150, p. 76-85, 1985.

STENZEL, M. Solubilização Enzimática de Proteína do Farelo de Soja e Caracterização Funcional dos Hidrolisados Formados. 136 p. Tese (Doutorado em Engenharia Química) - Pós-Graduação em Engenharia Química, Universidade Estadual de Maringá, Maringá, PR. 2007.

STROHER, R. Hidrólise Enzimática da Proteína do Farelo de Soja. 74 p. Dissertação (Mestrado em Engenharia Química) - Pós-Graduação em Engenharia Química, Universidade Estadual de Maringá, Maringá-PR, 2010.

STROHER, R.; ROSSI, R. A. S.; LARA, I.; ZANIN, G. M.; PEREIRA, N. C. Utilização da Enzima Alcalase na Hidrólise do Farelo de Soja. In: IX SIMPÓSIO DE HIDRÓLISE ENZIMÁTICA DE BIOMASSAS, Maringá. Anais. Maringá: Universid ade Estadual de Maringá, 2009.

VILARTA, R.; GUTIERREZ, G. L.; CARVALHO, T. H. P. F.; GONÇALVES, A. (Org.). Qualidade de Vida e Novas Tecnologias. Campinas: Ipes Editorial, 2007. 222 p.

WU, J.; MUIR, A. D. Isoflavone during protease hydrolysis of defatted soybean meal. Food Chem., v. 118 , p. 328-332, 2010. 